\title{
The Exploration and Practice on the Classroom Teaching Reform of the Database Technologies Course in colleges
}

\author{
Xiaodan ZHANG ${ }^{1, a, *}$, Xiaoying WANG ${ }^{2, b}$, Zhiqiang LIU $^{3, c}$, \\ Wandong $\mathrm{XUE}^{4, \mathrm{~d}}$ and Xiaolan $\mathrm{ZHU}^{5, \mathrm{e}}$ \\ $1,2,3,4,5$ Qinghai University, Xining 810016, China \\ a Email: 395049774@qq.com b Email: 10853243@qq.com \\ cEmail: 2577972@qq.com d Email: 576724723@qq.com \\ eEmail:986712452@qq.com \\ ${ }^{*}$ Corresponding author
}

Keywords: Teaching Reform, Classroom Teaching, Mixed Teaching Mode

\begin{abstract}
The classroom teaching in colleges and universities plays an important role in the process of talent training. How to improve the quality of classroom teaching is a key topic for colleges to carry out the related research on education reform and innovation. While the reform of the teaching mode is the key point, it's also a topic worthy of discussion and practice. In this paper, several effective classroom teaching measures from the aspects of the reform and innovation of teaching content, teaching methods, teaching evaluation and assessment model and so on, will be discussed. They are applied for improving the student's ability of receiving and digesting professional knowledge, as well as to improve their practical ability to analyze and solve problems. By taking the course of database technologies and applications of Qinghai University as an example, the teaching measures mentioned in this paper are practiced. The results show that they are effective, referenced and popularized. There hopes that those measures will provide valuable references to the related teaching and research, as well as the other classroom teachings.
\end{abstract}

\section{Introduction}

Education is the important cornerstone of the nation's rejuvenation and the progress of the society. In the 19th major reports of the party, the priority of development of educational undertakings is indicated clearly. Building a powerful county in education is a basic project for the great rejuvenation of our nation ${ }^{[1]}$. So we must give priority to education and speed up the modernization of it, as well as to construct the people's satisfied education. It can be seen that education is of great significance in the development strategy of our nation. While as important bases for training professionals and innovative talents, the education of colleges and universities is particularly important, which ensures the adequate supply of skilled talents. As a college educator, we should awareness our responsibility of education from the thought and the attitude, excepting to respond to the spirit of the 19th major reports of the party activity, we also should seriously consider how to improve the quality of college education and explore effective classroom teaching measures, so as to train high-quality professional talents for the society.

In this paper, the course of database technologies and applications in Qinghai University is taken as the research object. Some effective classroom teaching measures are explored and practiced from the aspects of the construction of teaching content, teaching model, teaching team, teaching evaluation and assessment method. The result shows that the application of integrated teaching measures by other a variety of ways can let the students change to active knowledge explorers from the passive receivers. Through the network platform to provide the rich resources for student at the same time, it also gives full play to the subjective initiative of the students, as well as to improve the quality of classroom teaching and achieve a good effect. 


\section{The Exploration and Reform on Classroom Teaching Measures}

The database technologies and applications course of Qinghai University is a course with very strong theory and practice. The traditional teaching method is difficult to guarantee the classroom effect and the students' ability to accept knowledge and digest knowledge is also low. In addition, due to the continuous updating of database technology, our teaching reform measures are mainly focused on the reform and innovation of teaching content, teaching team, teaching mode and evaluation mechanism. Based on the relatively mature teaching mode, such as mixed teaching mode, several effective teaching measures are explored and summarized as follows.

\subsection{The practice on Teaching Content reform}

With the development and updating of database technology, the content of computer courses should be constantly updated. Therefore, we must constantly supplement and improve teaching contents in every round of course and consider how to train students' knowledge and practical ability better. The key for the effective reform of the content of course is to update the teaching and experimental modules and design the refined courseware. The specific process mainly includes the refining the theory of classroom teaching knowledge and the optimization of the time allocation by integrating of several classic course, such as the database concept and database design. Ensure that while explaining the basic theoretical knowledge of classics, the advanced and excellent database technology can be timely introduced, such as block chain technology.

\subsection{The practice of teaching mode innovation}

The measure on exploring a teaching model that suitable for students will improve the enthusiasm of students to acquire knowledge to a great extent ${ }^{[2]}$. In this paper, a teaching method combined a variety of teaching models is adopted, which are described as follows.

2.2.1 Mixed teaching mode:

In practice, by understanding the cognitive structure of students and grasping the positioning of students' training objectives and curriculum in their tarring programs, the short micro-videos on the key knowledge points of course are designed ${ }^{[3]}$. Then they are published and shared independently by building special online teaching sharing resources platform. While for the offline teaching part, the way of teaching students in accordance with their aptitude is adopted. By assigning gradient tasks, the needs of knowledge acquisition and practice of students in different degrees are meet.

\subsubsection{Project teaching mode:}

In the course of teaching, through relying on practical research projects, students can participate in the comprehensive application of database technology in practical projects and train their comprehensive knowledge practice ability. The specific implementation process is as follows: the students are divided into several groups and given a specific topic to complete the whole process of research, including information collection, system design, programming debugging and evaluation. Through the project, students can understand the basic requirements and application of the knowledge in every link of the project.

\subsubsection{Discussion teaching mode:}

This mode is based on the premise of online self-regulated learning; the discussion topic about a key knowledge point is designed and published before each class. In our class, some time (8-10 minutes for example) is reserved for discussion and students are invited to express their views actively. By this process, the students' self-learning degree about the new knowledge is generally acquired, which is more advantageous to the time distribution of knowledge point in the following teaching links. At the same time, their discussion and performance are included in the assessment, which can improve the enthusiasm of the students to a certain extent.

\subsubsection{Demonstrative teaching mode:}

This mode is mainly applied for the practical teaching of experimental courses. In the practice course, some students are assigned to operate the experimental content and the others will study synchronously. Once a problem is encountered, we will analyze and discuss the solution together. By this way, the students are urged to preview before class and there also have a certain pressure in 
the practice class. It not only breaks the silence in class, but also trains students' ability to apply to knowledge.

\subsection{The practice and innovation of student assessment way}

The process oriented assessment method is adopted in our teaching reform measures in this paper. We increase the proportion of usual performance in students' total examination results and refine every score of usual performance. The specific assessment proportion is shown as Fig.1.

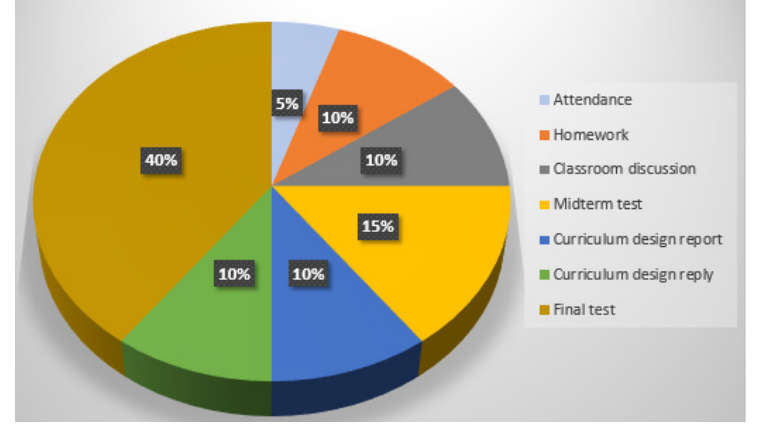

Fig.1 The assessment proportion of students' score

In addition, the way of paperless examination is applied by constructing and improving of database test question bank continuously. The question bank is not open to students at usual, thus it can avoid the phenomenon of students' mechanical practice. The way can improves the efficiency of evaluation of students' achievement by setting up the scoring point of the question bank.

\subsection{The practice and innovation of teaching effect evaluation mechanism}

The evaluation of classroom teaching can reflect the effect of the implementation of classroom teaching measures. Therefore, it's necessary to establish an effective evaluation mechanism. In this paper, the teaching effect is mainly reflect by classroom teaching feedback. With the aid of electronic questionnaire platform, the effective electronic questionnaire that can really reflect the situation of classroom teaching is designed. Then we can get the students' acceptance of each setting of the course teaching mode objectively, while just only take them a small amount of time in the classroom. The timely understanding of the students' dynamics can help teachers to adjust the teaching content, process or the corresponding teaching mode in time.

\subsection{The construction of teaching team}

A young and energetic middle-aged team is the guarantee of the smooth development of the teaching work and the effect of the classroom teaching. In the effective teaching measures discussed in this paper, we mainly select course group members to participate in related course actively, such as training, academic exchanges and so on, so as to enhance the construction of teaching team for improving the teaching level of the whole team.

After the completion of the construction of the teaching team, the way of teaching a same course with different multiple teachers is adopted ${ }^{[3]}$. The testing database course is divided into several key parts, for example, the part of basic programming language design, relational specification theory, database system design and embedded programming development and so on. And the each divided part is taught by different teacher in the course group, which for giving full play to the expertise of teachers and improving the effectiveness of the course teaching.

\subsection{The implementation of sharing of teaching resources}

One of the key effective measures discussed in this paper is the opening of the teaching resource sharing program. The platform of database teaching sharing resources is researched and developed independently to realize all the resources on our database course to be shared, such as multimedia courseware, experimental instructor, teaching cases and exercises library. The functions of the teaching resource sharing platform developed for our database course is shown as Fig.2.

The functions such as user account management, permission management, uploading and publishing of teaching resources, online access, online communication and discussion, operation log 
recording are provided by the sharing platform. The rich function modules and friendly interaction interface give a great convenience for teaching resources sharing and students' autonomous learning. It also provides support for their process learning assessment.

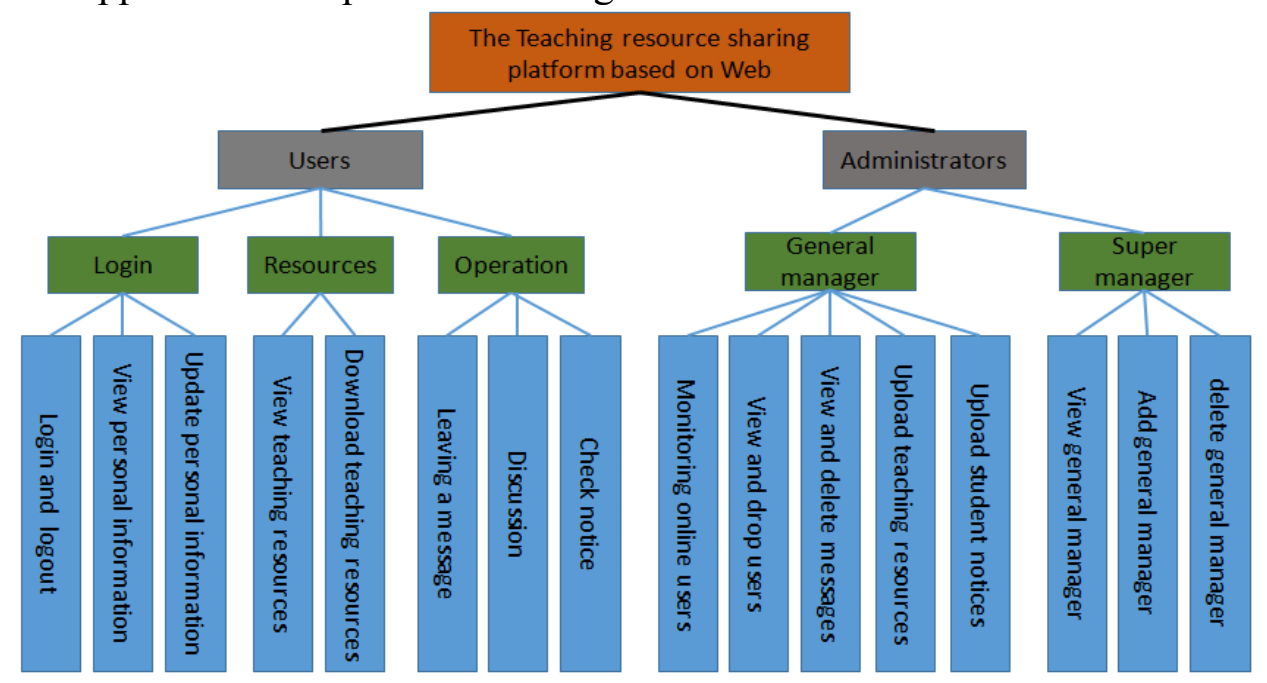

Fig.2 The functions of teaching resource sharing platform for database course

\section{Summary}

Several classroom teaching reform and innovation measures from the aspect of the teaching content, teaching team, teaching mode, teaching evaluation and teaching resources sharing are explored and practiced in this paper. The course of database technologies and applications is treated as the test course and the testing results show that it achieves a certain degree of teaching effectiveness. The efforts made by the authors have accumulated rich teaching resources and valuable teaching experience for curriculum construction and hoping that the measures discussed above can provide valuable references for related research or other classroom teaching. However, although we have made great efforts in the reform and innovation of classroom teaching mode and the enriching and perfecting on the teaching resource, the subjective initiative of students' learning and the matching degree between the cognitive structure of the students and the knowledge system of our testing course, which is still a fundamental problem affecting the effect of classroom teaching and it still needs to be further exploration and solved.

\section{Acknowledgement}

This research was financially supported by the key course construction project of Qinghai University (No.2017ZYHXKC21), the graduate course construction project of Qinghai University (No.qdyk-170112) and the intelligent information processing technology teaching team project of Qinghai University (No.TD1814).

\section{References}

[1] Network Resource: https://www.guancha.cn/politics/2017_10_27_432557.shtml

[2] Z.Liu. Measures to improve the quality of teaching in Higher Vocational Colleges (2017). Network resource: http://www.21ks.net/lunwen/jx1ll1/85412.html

[3] Xiao-dan ZHANG, Xiao-ying WANG, Zhi-qiang LIU and Lu WANG. The Research on the Reform of Classroom Teaching in Colleges. 2017 2nd International Conference on Education, Management and Systems Engineering, 2017.5, Beijing 